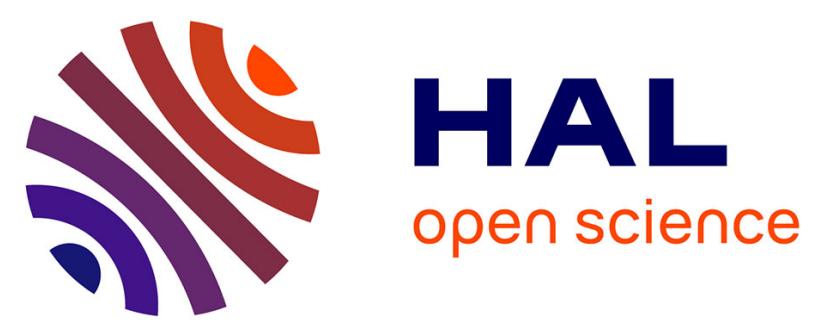

\title{
Total Cost of Ownership Driven Methodology for Predictive Maintenance Implementation in Industrial Plants
}

\author{
I. Roda, S. Arena, M. Macchi, P. F. Orrù
}

\section{- To cite this version:}

I. Roda, S. Arena, M. Macchi, P. F. Orrù. Total Cost of Ownership Driven Methodology for Predictive Maintenance Implementation in Industrial Plants. IFIP International Conference on Advances in Production Management Systems (APMS), Sep 2019, Austin, TX, United States. pp.315-322, 10.1007/978-3-030-30000-5_40. hal-02419247

\section{HAL Id: hal-02419247 \\ https://hal.inria.fr/hal-02419247}

Submitted on 19 Dec 2019

HAL is a multi-disciplinary open access archive for the deposit and dissemination of scientific research documents, whether they are published or not. The documents may come from teaching and research institutions in France or abroad, or from public or private research centers.
L'archive ouverte pluridisciplinaire HAL, est destinée au dépôt et à la diffusion de documents scientifiques de niveau recherche, publiés ou non, émanant des établissements d'enseignement et de recherche français ou étrangers, des laboratoires publics ou privés. 


\title{
Total Cost Of Ownership Driven Methodology For Predictive Maintenance Implementation In Industrial Plants
}

\author{
I. Roda ${ }^{1 *}$, S. Arena ${ }^{2}$, M. Macchi ${ }^{1}$ and P.F. Orrù ${ }^{2}$ \\ ${ }^{1}$ Politecnico di Milano, Dipartimento di Ingegneria Gestionale, Piazza Leonardo da \\ Vinci 32, Milan, Italy \\ ${ }^{2}$ Dipartimento di Ingegneria Meccanica, Chimica e dei Materiali, University of \\ Cagliari, Via Marengo 2, Cagliari, Italy \\ irene.rodaepolimi.it
}

\begin{abstract}
This paper proposes a methodology to drive from a strategic point of view the implementation of a predictive maintenance policy within an industrial plant. The methodology integrates the evaluation of system performances, used to identify the critical components, with simulation and cost analysis. The goal is to evaluate predictive maintenance implementation scenarios based on alternative condition monitoring (CM) solutions, under the lenses of Total Cost of Ownership (TCO). This allows guiding the decision on where in the industrial system to install diagnostic solutions for monitoring of asset health, by keeping a systemic and life cycle-oriented perspective. Technical systemic performances are evaluated through Monte Carlo simulation based on the Reliability Block Diagram (RBD) model of the system. To validate the methodology, an application case study focused on a production line of a relevant Italian company in the food sector is presented.
\end{abstract}

Keywords: Predictive maintenance, Total Cost of Ownership, Condition monitoring, decision-making.

\section{Introduction \& State of the Art}

This work presents a methodology aimed at supporting the implementation of predictive maintenance in industrial applications by providing a strategic guideline. The final aim of the methodology is to support industrial engineers in defining where in the industrial system to install technologies for collecting monitoring data and which type of solution to select. The concept of predictive maintenance, is widely analysed in the scientific literature and it is more and more recognized as a potential area for getting benefits for manufacturing companies thanks to the possibilities provided by the new technologies. However, in the literature some limitations for the development of industrial applications in the real world are highlighted, and they include:

- lack of frameworks that can be used to guide decisions from a strategic point of view [1-4]. In fact, many authors introduce specific application cases of predictive maintenance implementation without providing general procedures that can be taken as a reference and generalized; 
- lack of simulation approach [5,6]. In fact, there is a lack of methodologies in the literature that exploit the possibility of implementing and analysing scenarios a priori through simulation, overcoming the problem of absence of historical data;

- lack of integration between economic evaluation and technical performance analysis for predictive maintenance implementation [6-9]. In fact, many authors have proposed an economic assessment only as simple review and feedback of performed maintenance activities to correct maintenance tasks without considering relationship between predictive maintenance and impact of Total Cost of Ownership (TCO).

Moreover, companies nowadays are facing a vast offer of solutions for predictive maintenance by technology providers and are expressing needs for having formal guidelines to understand where to address their investments.

The proposed methodology has the purpose of overcoming these criticalities with the aim to combine technical performance analysis with economic evaluation, representing a structured approach that supports the implementation of predictive maintenance activities in industrial applications. In the following Section 2 the main steps of the proposed methodology are described and in Section 3 an application case within the food sector is described.

\section{Methodology description}

The complete iterative procedure is reported in figure 1 , and is described in this section, step by step.

Step 1 - Context definition. The first step of the methodology consists in the clear identification of the context in which predictive maintenance activities should be introduced, defining the asset system (production plant) to be analysed and modelled. In this step it is important to clearly identify the type of production process involved; the reference objectives of the company and any industrial specific constraints (production capacity, budget, quality of products, performance indicators, layout configuration). All the elements defined in this step are key points for the guidelines definition in the elaboration of predictive maintenance approach in the industrial reality.

Step 2 - Cost Breakdown Structure (CBS) and Targets definition. The second step is aimed to build the cost model structure for the TCO of the reference asset system. In particular, the Cost Breakdown Structure (CBS) has to be defined at this step, including the relevant cost items along asset life-cycle [10,11]. Moreover, criteria and required parameters to estimate each item must be identified. The defined TCO model will be used to evaluate alternative scenarios for predictive maintenance implementation. Selection of adequate target levels in terms of net present value of TCO or payback time are also defined at this step.

Step 3 - System modelling. This step consists in system modelling which has two aims. On one side, a Failure Mode and Effect and Criticalities Analysis (FMECA) must be implemented in order to identify the asset system components (machines and 
functional sub-groups) and provide information on asset failure modes/causes and effects. This activity enables getting information on asset components degradation and its detectability. On the other side, the use of Reliability Block Diagram (RBD) is addressed in order to model the entire system including the impact of each component failure at system level [12].

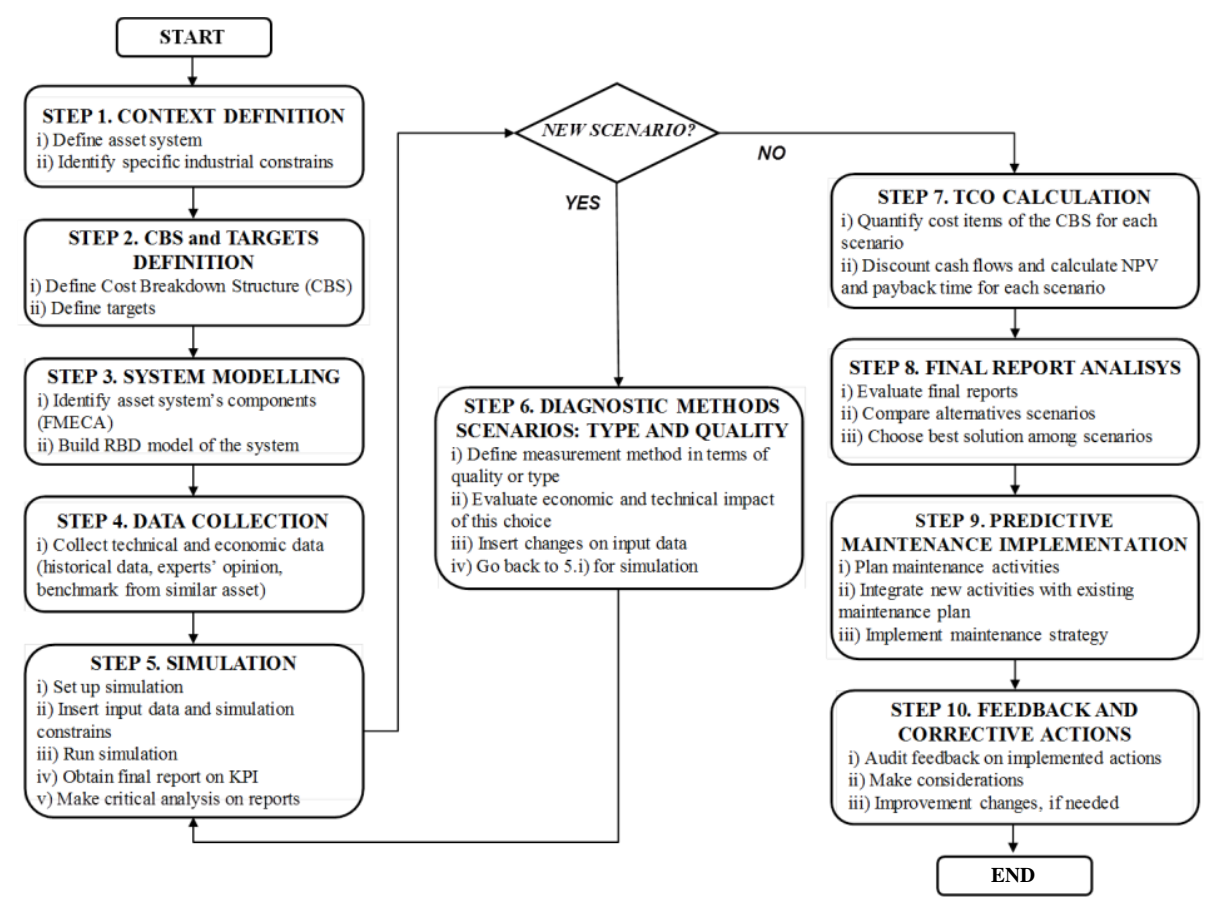

Fig. 1. Proposed iterative methodology.

Step 4 - Data collection. This step is dedicated to data collection. In particular, two types of input data should be considered, i.e. technical and economic data. Regarding the needed technical data to perform the performance analysis, for each component of the system, the probability density functions of TBF (time between failures) and TTR (time to repair) should be identified. Strategies to collect the data to define these distributions can refer to historical data register and fitting, in case collected data are available and reliable in terms of data quality, use of experts' opinion or pre-defined distributions/benchmark data from similar assets in case of no quality data of in case of no available data due to assets at their beginning of life stage (greenfield projects). Regarding the economic data, they are the ones needed to quantify the cost items in the CBS and to estimate the TCO of the asset. If they are not available, experts' opinion and benchmark data from similar asset/system could be used.

Step 5 - Simulation. Innovative step is the introduction of simulation to evaluate and compare several scenarios derived from different condition monitoring (CM) systems, exploiting Monte-Carlo technique, based on the RBD model of the plant. For each 
scenario, a set of independent histories that collect events on plant life as failures is obtained to generate samples from probability distributions, representing the expected future evolution of system status from initial to final time event [13]. The final result is a statistical estimate value of the performance of the complete system, expressed through a performance indicator such as Operational Availability, and of any of its sub-systems, under the specific simulated scenario conditions. This step is run for the case base scenario, enabling identified critical components within the system, and for any alternative scenarios defined in the following step, through and iterative procedure, enabling evaluating alternative CM solutions.

Step 6 - Diagnostic methods: type and quality. Based on criticality analysis of system components carried out in step 5, this step allows defining several scenarios (derived from different $\mathrm{CM}$ techniques on critical equipment) with the aim to select the best solution among proposed alternatives. This innovative step is directly connected to step 5 through a logical connector "New Scenario?", in order to regulate the generation of diagnostic methods scenarios, that bring modifications on system with respect to the AS-IS context already analysed in the previous step.

In particular, it enables to consider alternative types and installation locations of tools to monitor asset health and different expected level of quality of capability of the diagnosis and prognosis process. Moreover, it enables considering the economic impact of the solution. These elements are input for running again step 5 (simulation) for each alternative scenario and evaluating the impact of condition monitoring measurement systems on the system performance during its lifecycle.

Step 7 - TCO calculation. This step allows to evaluate each single scenario, predefined in the previous step, through TCO evaluation [14]. In this step, the CBS cost items are estimated (dependent/independent on the system technical performances) and cost flows discounted, quantifying the net present value for each scenario.

Step 8 - Final reports analysis. This step is based on the analysis of the results obtained from the estimation of the TCO in each scenario. In order to get to the final choice of the best alternative solution, an adequate documentation that summarizes main features of each conducted analysis should be provided through reports, diagrams and graphs based on both technical performance parameters and economic evaluation. The solution that ensures minimum TCO has to be selected while, if more than one solution satisfies this criterion and different scenarios have equal or similar TCO value, alternatives should be compared using other criteria, that have to be defined initially and that have a relevant meaning in performed analysis

Step 9 - Predictive maintenance implementation. This step refers to the planning and the implementation of the predictive maintenance activities based on the CM systems as chosen in the previous steps. Company should integrate CM systems with scheduling and planning of entire maintenance strategy. This step is relevant and not trivial because a correct integration between company strategy and defined maintenance activities, on critical machines in the production system, facilitates the exploitation of predictive approach, reducing costs and increasing efficiency of production. 
Step 10 - Feedback and corrective actions. Last step identifies feedback and review on performed maintenance activities and corrective actions through two main subphases. The first one is based on audit result and comparison with pre-defined objectives to provide information about technical and economic impact of predictive maintenance activities on the system performances. The second one is based on improvements implementation, if needed, which allow correction of maintenance activities, based on achieved results. If company decides to make changes because it is necessary to correct maintenance tasks or to introduce new CM techniques, it is identified by "YES" path in the proposed methodology. Thus, it is necessary to come back and define a new scenario, that represent changes required by company. This step completes the entire proposed procedure and it represents the key to obtain a dynamic methodology oriented to continuous improvement.

\section{Application case}

The proposed methodology is implemented in a numerical application carried out in collaboration with a relevant Italian food company with the aim to validate it. The case study is focused on an industrial plant, recently installed. The company expressed the need for a methodology that can be used to guide the definition of the maintenance policies for managing the plant and in particular, to focus the investments in predictive maintenance solutions. Through the methodology, the implementation of the first five steps, was done by the use of a Reliability Engineering software (R-MES ()) which supports Reliability Block Diagram modelling and Monte Carlo Simulation. The application is implemented only as a numerical experimentation thus, steps 9 and 10 are not included because they consist of practical activities only based on company cost-effective decisions and implement actions.

Based on the criticality analysis developed in phase 5 , two scenarios were selected in step 6 to be compared and evaluated. The scenarios address the installation of different diagnostic systems for monitoring wear on different critical components within the system. Moreover, each scenario is analysed considering two levels of diagnostic capability quality:

a. Best case: it is based on the assumption of perfect functioning of installed $\mathrm{CM}$ system and relative achieved benefits on system availability:

$$
\left(T B F_{\text {assets }}=T B F_{\text {assest AS-IS scenario }} \text { and TTR } R_{\text {assets }}=0\right)
$$

b. Worst case: it is based on the assumption that condition monitoring systems are not perfect in detecting failures and also, delays could affect restoration activities:

$\left(T B F_{\text {assets }}<T B F_{\text {assest } A S-I S \text { scenario }}\right.$ and $\left.T T R_{\text {assets }}=50 \% T T R_{A S-I S \text { scenario }}\right)$

Table 1 summarizes cost items as calculated in step 6 after running simulation (step 5) for each alternative scenario. It can be noticed that investment costs of scenario 2 are higher than investment cost of scenario 1 due to higher cost of adopted sensors. The time losses for installation of CM systems are identical while, the disposal 
costs in scenarios 2 are higher due to higher number of sensors installed. Energy consumption costs, associated to installed systems, in scenarios 2 are higher due to higher number of sensors, while production losses costs are reduced in scenario 2 due to higher overall system availability with respect to scenario 1. An important parameter considered is the availability of the production process since the introduction of sensors allows to reduce inefficiency associated to production losses.

Table 1. Summary of economic cost items for proposed scenarios.

\begin{tabular}{|c|c|c|c|c|c|}
\hline Cost item & \multicolumn{4}{|c|}{ Economic value } & \multirow[t]{2}{*}{ Description } \\
\hline $\begin{array}{c}\text { Una-tantum } \\
\text { costs }\end{array}$ & Scenario 1a & Scenario $1 b$ & Scenario $2 \mathrm{a}$ & Scenario $2 b$ & \\
\hline $\begin{array}{l}\text { Investment } \\
\text { cost }\end{array}$ & $\begin{array}{c}28000 € \\
(\text { year } t=0)\end{array}$ & $\begin{array}{c}28000 € \\
(\text { year } t=0)\end{array}$ & $\begin{array}{c}32500 € \\
(\text { year } t=0)\end{array}$ & $\begin{array}{c}32500 € \\
(\text { year } t=0)\end{array}$ & $\begin{array}{l}\text { Acquisition of } \\
\text { sensors and } \\
\text { software }\end{array}$ \\
\hline $\begin{array}{l}\text { Cost due to } \\
\text { plant down- } \\
\text { time for in- } \\
\text { stallation }\end{array}$ & $\begin{array}{c}28080 € \\
(\text { year } t=0)\end{array}$ & $\begin{array}{c}28080 € \\
(\text { year } t=0)\end{array}$ & $\begin{array}{c}28080 € \\
(\text { year } t=0)\end{array}$ & $\begin{array}{c}28080 € \\
(\text { year } t=0)\end{array}$ & $\begin{array}{l}\text { Production } \\
\text { losses for CM } \\
\text { systems }\end{array}$ \\
\hline Disposal cost & $\begin{array}{c}400 € \\
(\text { year } \mathrm{t}=20)\end{array}$ & $\begin{array}{c}400 € \\
(\text { year } \mathrm{t}=20)\end{array}$ & $\begin{array}{c}500 € \\
(\text { year } t=20)\end{array}$ & $\begin{array}{c}500 € \\
(\text { year } \mathrm{t}=20)\end{array}$ & $\begin{array}{l}\text { Recovery or } \\
\text { dismiss CM } \\
\text { techniques }\end{array}$ \\
\hline \multicolumn{6}{|l|}{ Yearly costs } \\
\hline $\begin{array}{l}\text { Energy con- } \\
\text { sump. }\end{array}$ & $1200 € /$ year & $1200 € /$ year & $1500 € /$ year & $1500 € /$ year & $\begin{array}{l}\text { Energy con- } \\
\text { sumption by } \\
\text { CM system }\end{array}$ \\
\hline $\begin{array}{l}\text { Production } \\
\text { losses costs }\end{array}$ & $\begin{array}{c}-64228.32 \\
€ / \text { year }\end{array}$ & $\begin{array}{c}-21864.96 \\
€ / \text { year }\end{array}$ & $\begin{array}{c}-79260.48 \\
€ / \text { year }\end{array}$ & $\begin{array}{c}-25964.64 \\
€ / \text { year }\end{array}$ & $\begin{array}{l}\text { Savings costs } \\
\text { for availability } \\
\text { increase }\end{array}$ \\
\hline
\end{tabular}

The availability comparison between base case $(\mathrm{A}=81.57 \%)$ and different proposed scenarios, as well as total annual equivalent cost (CTAE) and the payback time (discounting rate of $5 \%$, as used by the company for investments evaluation) are assessed in table 2 .

Table 2. Summary of availability and TCO calculation for proposed scenarios.

\begin{tabular}{lcccc}
\hline & Scenario 1a & Scenario 1b & Scenario 2a & Scenario 2b \\
\hline Availability* & $83.45 \%$ & $82.21 \%$, & $83.89 \%$ & $82.33 \%$ \\
$\Delta$ Availability & +1.88 & +0.64 & $+2,32(2.77$ & $+0.76(0.92$ \\
& $(2.25 \%)$ & $(1.5 \%)$ & $\%)$ & $\%)$ \\
Payback Time & $<1$ year & $<2$ years & $<1$ year & $<2$ years \\
CTAE & $-58851.39 €$ & $-16488.03 €$ & $-73246.48 €$ & $-19950.64 €$ \\
*Availability is estimated through Monte Carlo simulation running 10.000 iterations \\
\hline
\end{tabular}


All scenarios provide an increment of system availability thus, all proposed solutions are cost-effective respect case base, even if each of them has a different impact on overall system availability. Payback time is less than 1 year in best condition while investment costs are recovered in 2 years in worst operating condition. Best solution is scenario 2 that provides a higher increment of technical system availability despite a higher investment due to higher investment cost. Moreover, scenario 2 shows the lowest TCO value representing best investment during entire plant lifecycle since it provides a high reduction of production losses costs.

\section{Discussion and conclusions}

This work concerns the definition of an innovative methodology that provides support for investment and management decisions for predictive maintenance implementation in industrial plants. In detail, key strength points are:

- the definition of practical methodology to implement predictive maintenance activities through a significant integration between technical performance evaluation (RAM analysis) and economic assessment (TCO evaluation);

- the combination between RBD model with discrete events simulation based on Monte Carlo technique, through exploitation of R-MES software, for estimation of technical system performances along its lifecycle under different CM scenarios;

- the introduction of an innovative step for the generation of the alternative CM scenarios for evaluating the impact of different types of monitoring systems and quality of diagnostic capabilities, through simulation and TCO estimation;

- finally, the validation of proposed methodology within an important Italian food company.

The methodology was actually positively valued by the managers of the company which recognize, as its main potentialities the easiness of application, satisfying company requirements; the overcoming of the criticality associated to absence of historical data, through the introduction of the simulation phase and the possibility of exploiting several data collection strategy; and, the integration of TCO estimation as principal tool for the evaluation of generated scenarios, providing the possibility of considering whole plant life-cycle. After the application case implementation, the company decided to develop a pilot project to evaluate the investment in the solution provided by the proposed decision-making methodology.

Overall, the defined methodology represents a good decision-making support to identify critical components, on which predictive maintenance activities should be implemented. In fact, it allows to manage a better utilisation of resources because it avoids the installation of $\mathrm{CM}$ systems on machines and components, that in reality, are not the most critical ones. 


\section{References}

1. Faccio M., Persona A., Sgarbossa F., Zanin G.: Industrial maintenance policy development: A quantitative framework. International Journal of Production Economics. 147(A), 85-93 (2014).

2. Sgarbossa F., Zennaro I., Florian E., Persona A.: Impacts of weibull parameters estimation on preventive maintenance cost. IFAC-PapersOnLine. 51(11), 508-13 (2018).

3. Allah Bukhsh Z., Saeed A., Stipanovic I., Doree A.G.: Predictive maintenance using treebased classification techniques: A case of railway switches. Transportation Research Part C: Emerging Technologies. 101, 35-54 (2019).

4. Matyas K., Nemeth T., Kovacs K., Glawar R.: A procedural approach for realizing prescriptive maintenance planning in manufacturing industries. CIRP Annals Manufacturing Technology. 66(1), 461-464 (2017).

5. BSI. ISO 17359, Condition monitoring and diagnostics of machines - General guidelines. International Organization for Standardization ISO. 1-38 (2011).

6. Al-Najjar B.: On establishing cost-effective condition-based maintenance. Journal of Quality in Maintenance Engineering. 18(4), 401-16 (2012).

7. Zachariassen F., Arlbjørn J.S.: Exploring a differentiated approach to total cost of ownership. Industrial Management and Data Systems. 111, 448-469 (2011).

8. Afrinaldi F., Taufik, Tasman A.M., Zhang H.C., Hasan A.: Minimizing economic and environmental impacts through an optimal preventive replacement schedule: Model and application. Journal of Cleaner Production. 143, 882-93 (2017).

9. Gogu C., Wang Y., Haftka R.T., Bes C., Kim N.H., Binaud N.: A cost driven predictive maintenance policy for structural airframe maintenance. Chinese Journal of Aeronautics. 30(3), 1242-1257 (2017).

10. Woodward D.G.: Life cycle costing - Theory, information acquisition and application. International Journal of Project Management. 15(6), 335-344 (1997).

11. Enparantza R., Revilla O., Azkarate A., Zendonia J.: A Life Cycle Cost Calculation and Management System of Machine Tools. In: The 13th CIRP International Conference on Life Cycle Engineering, Katholieke Universiteit Leuven, Belgium, 717-22 (2006).

12. Birolini A.: Reliability Engineering. Springer Berlin Heidelberg. (2007).

13. Zio E.: The Monte Carlo Simulation Method for System Reliability and Risk Analysis. Springer Berlin Heidelberg. (2013).

14. Roda I., Garetti M.: TCO Evaluation in Physical Asset Management: Benefits and Limitations for Industrial Adoption. IFIP Advances in Information and Communication Technology. 440(3), 216-23 (2014). 